\title{
Physical characterization of porous hydroxyapatite scaffolds
}

\author{
Anita JL ${ }^{1 *}$, Sundareswari $\mathrm{M}^{2}$, Ravichandran $\mathrm{K}^{3}$ and BavaniLatha $\mathrm{M}^{3}$ \\ ${ }^{1}$ Department of Physics, Sathyabama Institute of Science and Technology, Chennai-600 119, India \\ ${ }^{2}$ Dean (S\&H),Department of Physics, Sathyabama Institute of Science and Technology, Chennai-600 119, India \\ ${ }^{3}$ Head,Department of Analytical Chemistry,University of Madras, Chennai- 600025, India
}

\begin{abstract}
Cellulose obtained from the bark, wood or leaves of plants is a natural binder which possesses many unique properties. Many synthetic binders are biodegradable and can be tailor-made easily. However, cellulose is completely biodegradable polymers and has potential applications in biomedical and environmental fields. Therefore, it received great attention and was extensively investigated. In the current work porous hydroxyapatite scaffolds are prepared by polymeric replication method using cellulose (a natural binder). The influence of binder concentration on the structure and mechanical properties of scaffold is studied. HAP scaffolds are characterized for phase purity, structural analysis and mechanical properties. It is inferred that it is possible to produce bio compatible hydroxyapatite scaffolds with highly inter connected macro and micro pores with an ultimate compressive strength of $0.65 \mathrm{MPa}$.
\end{abstract}

\section{Introduction}

Tissue engineering is a field where cells bone/ scaffolds and signals/factors are mutually joined with the endeavour to re-establish, preserve and improve tissue and organ utility. Calcium phosphates are amongst the most widely used resources for bone tissue regeneration. They can be man-made as gels, pastes and solid blocks or even as porous matrices, with orthopaedics and dentistry being their main areas of relevance. Hydroxyapatite (HAP) are the most frequently used calcium phosphates, owed to their Stoichiometric ratio $(\mathrm{Ca} / \mathrm{P})$ ratios close to that of natural bone and also for their stability when in contact with physiological environment. HAP is a major constituent of bone resource and is resorbed after a long time in the body, due to its biocompatibility [1]. The porous network or interconnected pores in HAP structure permit the tissue to penetrate, which further enhances the implant tissue attachment [2].

Several methods have been investigated to achieve the required porous scaffolds. Sopyan, et al. has studied with pore-creating volatile particles, ceramic foaming methods and polymeric sponge process [3]. The polymeric sponge technique, which offers great flexibility, is particularly of interest due to its greater advantages such as opportunity to control the pore size, forseveral required complex shapes and straightforward process (Tian and Tian 2001). on the other hand, the properties of the Hydroxyapatite scaffold prepared through the polymeric sponge technique highly depending on the slurry properties together with homogeneity, rheology and dispersion. Monmaturapoj has reported the dispersant on the rheological behaviour of concentrated hydroxyapatite suspensions [4]. In this study, porous hydroxyapatite scaffolds were obtained using the polymer replication method, using cellulose as a binding agent and the morphology and its physio-chemical properties were studied. The structure of cellulose is shown in Figure 1, it is an polysaccharide and an organic compound with the formula $(\mathrm{C} 6 \mathrm{H} 10 \mathrm{O} 5)_{\mathrm{n}}$, and also an important structural component of the primary cell all of green plants. It is one of the most abundant organic polymer on Earth, which constitutes to about $90 \%$ in cotton fibre, $40-50 \%$ in wood and approximately $57 \%$ in dried hemp. Hence, these scaffolds made from cellulose can be used as matrices for bone tissue engineering or as specific release vehicles. Also, they may be functionalized with molecules such as collagen, Chitosan, etc, in order to enhance their biological responses [5].

\section{Material and Methodology}

Sample Preparation: The Hydroxyapatite powder with an average crystallite size of approximately40nm was prepared according to our previous work by sol-gel [6,7]. The template used to prepare scaffolds were polyurethane sponges with an average pore size of 400 microns. The Cellulose used as a binder was made into a homogenous mixture by mixing for $2 \mathrm{~h}$ with water at $50^{\circ} \mathrm{C}$. To fabricate scaffolds, a ceramic slurry containing $6 \mathrm{~g}$ of Hydroxyapatite powder, binder, tensioactive agent (A40V Dispexfrom BASF) and water [8] were blended again for $2 \mathrm{~h}$ to disperse thoroughly. The template was removed by heating in a muffle furnace at $600{ }^{\circ} \mathrm{C}$ for $2 \mathrm{hrs}$, followed by the densification of scaffold by sintering at $1150{ }^{\circ} \mathrm{C}$ for $4 \mathrm{~h}$. Now, these prepared scaffolds were cut into cubes for further characterization.

\section{Physio-Chemical Characterization}

The microstructure of the hydroxyapatite scaffolds were characterized using optical stereo zoom microscope. The phase purity of the Hydroxyapatite scaffolds was determined by X-ray diffraction using a X'pertPro, Philips, TheNetherlands with $\mathrm{CuKa}$ radiation over the $2 \theta$ range of $10^{\circ}-80^{\circ}$ with a step size of $0.05^{\circ}$. The functional group analysis of HAP scaffolds was carried out in the spectral range from 4000to $650 \mathrm{~cm}-1$ using a single beam Fouriertransform infrared spectrometer (Agilent, Cary 630). The compressive strength

${ }^{*}$ Correspondence to: Anita Lett J, Department of Physics, Sathyabama Institute of Science and Technology, Chennai-600 119, India, E-mail: anitalett@yahoo.co.in

Key words: hydroxyapatite scaffolds, 3D porous structure, natural gum, cellulose, compressive strength

Received: June 19, 2018; Accepted: June 27, 2018; Published: June 29, 2018 
of scaffolds were tested with an INSTRON materials testing machine (model 3365, Instron Corp., UK) using a cross-head speed of $1 \mathrm{~mm} /$ min with a maximum load of $30 \mathrm{~N}$ load cell. The porosity and density measurements of the scaffolds were calculated by simple displacement techniques [8].

\section{Results and Discussions}

It is found that the scaffolds replicated the pores in the sponges with a pore size of approximately 500 microns. Thus, highly porous Hydroxyapatite scaffolds were produced using the polymer replication method as seen in Figure 1. With SEM observations, pore diameters ranging from 400 to $500 \mu \mathrm{m}$ were observed. On the other hand, micropores of size lesser than micron werealso visualised in the pore walls and wall struts. The open as well as interconnected pore network was an essential factor for the scaffold to permit cell growth and the transportation of nutrients and metabolic waste. Gotz, et al. has reported that poresizes around $300 \mu \mathrm{m}$ were suggested for implants due to improved new bone and capillary formation. Hollister, et al. [9] conducted in vivo studies on HAP scaffolds with pore diameters ranging between $400 \mu \mathrm{m}$ and $1200 \mu \mathrm{m}$ and inferred no significant difference in bone growth for scaffolds of all poresizes (Table 1).

The XRD patterns of the scaffolds prepared is shown in Figure 2. All of the peaks matched with the JCPDS pattern 09-0432 for HAP, which suggested that no other phases were present, as shown in Figure 3. All of the peaks were attributed to the HAP phase and no additional peaks were observed. The results indicated that the HAP did not decompose after sintering. The characteristic peaks at two theta $31.7^{\circ} \mathrm{C}$ corresponding to (211) diffraction became narrower and sharper for sintering temperature $1150^{\circ} \mathrm{C}$. These data confirm that the major phase as Hydroxyapatite and absence of impurity such as calcium phosphates and calcium oxide are clearly identified.

The FT-IR spectra of the synthesized HAP scaffold prepared using cellulose as a binding agent is shown in Figure 4. In the FTIR spectra, the bands at 3570 and $630 \mathrm{~cm}^{-1}$ [7] were recognized to the hydroxyl stretching bands and bending bands of HAP, respectively. The broad absorption band from 3600 to $3300 \mathrm{~cm}^{-1}[10]$ indicated the existence of the bending mode of absorbed water. The bands at 1093 and $1041 \mathrm{~cm}^{-1}$ were assigned antisymmetric $03\left[\mathrm{PO}_{4}{ }^{3-}\right] \mathrm{P}-\mathrm{O}$ stretching mode and the $01 \mathrm{P}-\mathrm{O}$ symmetric stretching mode was detected at $962 \mathrm{~cm}^{-1}$ [9]. The bands at 603 and $569 \mathrm{~cm}^{-1}$ were attributed to components of the triply degenerate $04 \mathrm{O}-\mathrm{P}-\mathrm{O}$ bending modes (table 2 ).

The Scaffold prepared using cellulose showed high porosity of $75 \%$ with apparent density of $0.944 \mathrm{~g} / \mathrm{cm}^{3}$.It was able to tolerate a maximum

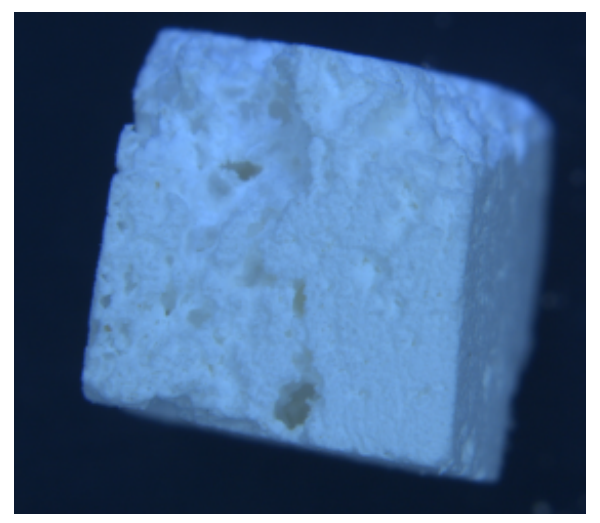

Figure 1. Synthesised HAP Scaffold.

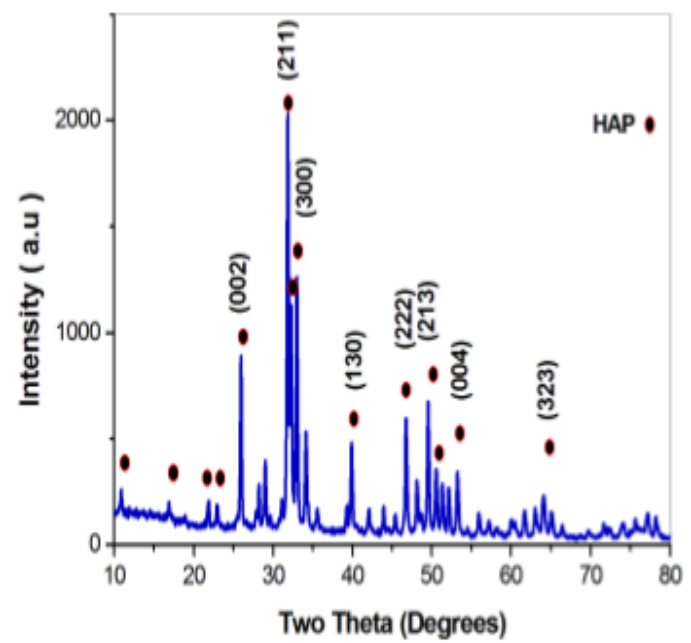

Figure 2. XRD pattern evenly distributed.

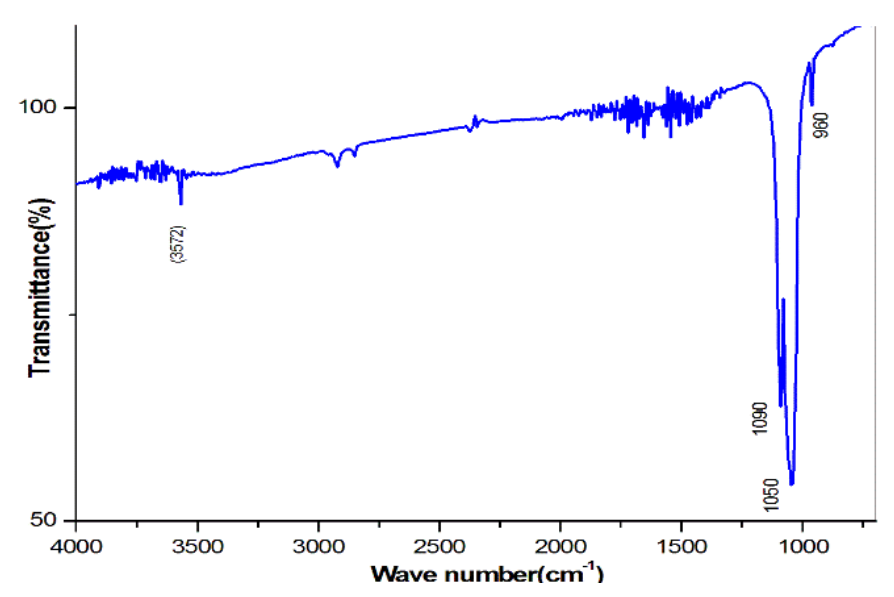

Figure 3. FTIR of Sintered Scaffold.

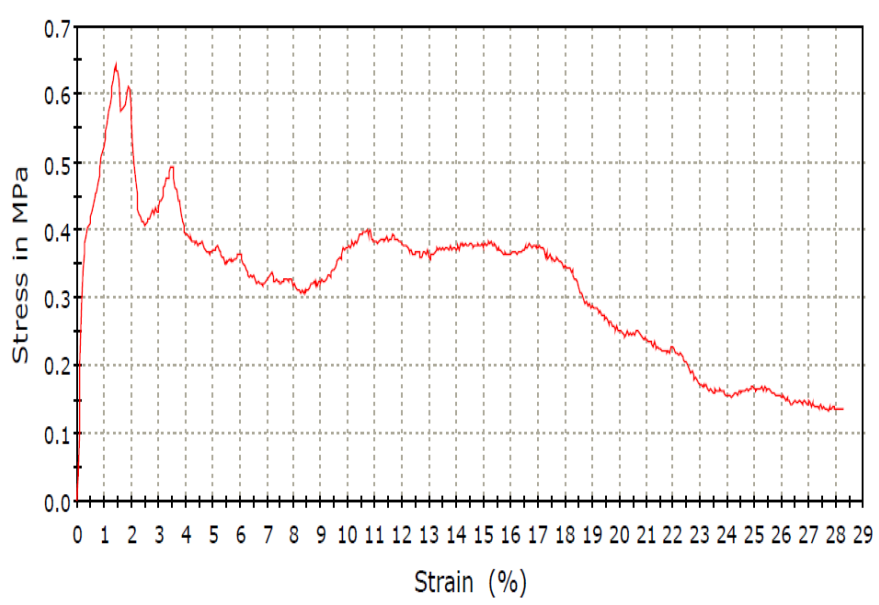

Figure 4. Stress - Strain analysis.

stress $0.65 \mathrm{MPa}$. The mechanical properties are strongly subjective by apparent density [11]. In trabecular bone,the apparent density ranges from $0.14 \mathrm{~g} / \mathrm{cm}^{3}$ to $1.10 \mathrm{~g} / \mathrm{cm}^{3}[11]$. Porosity is based on the presence ofopen pores. It was found that mechanical properties varied with binders used. Moreover, a few studies [12] have reported that the decomposition of HAP would reduce its mechanical properties. 
Table 1. Lattice constant.

\begin{tabular}{|c|c|c|c|c|c|c|c|}
\hline \multicolumn{8}{|c|}{ Lattice Information: } \\
\hline Phase name & $\mathrm{a}\left(\mathrm{A}^{\circ}\right)$ & $\mathrm{b}\left(\mathrm{A}^{\mathrm{o}}\right)$ & $\mathrm{c}\left(\mathrm{A}^{\mathrm{o}}\right)$ & $\begin{array}{l}\text { Alpha } \\
\text { (deg) }\end{array}$ & $\begin{array}{l}\text { Beta } \\
(\text { deg })\end{array}$ & $\begin{array}{l}\text { Gamma } \\
\text { (deg) }\end{array}$ & $\begin{array}{l}\text { Vol } \\
\left(\mathrm{A}^{\circ}\right)\end{array}$ \\
\hline Hydroxyapatite & 9.406674 & 9.406674 & 6.87543 & 90 & 90 & 120 & 527.083 \\
\hline
\end{tabular}

Table 2. Compressive Stress-Strain.

\begin{tabular}{|l|l|}
\hline Area $\left(\mathrm{mm}^{2}\right)$ & Modulus (Automatic) $(\mathrm{MPa})$ \\
\hline 52.70670 & 160.31806 \\
\hline $\begin{array}{l}\text { Compressive Strain at yield point (Zero } \\
\text { slope) }(\mathrm{mm} / \mathrm{mm})\end{array}$ & $\begin{array}{l}\text { Compressive Stress at yield point (Zero } \\
\text { slope) }(\mathrm{MPa})\end{array}$ \\
\hline 0.01430 & 0.6644 \\
\hline Compressive Stress $\left(\mathrm{mm}^{2}\right)$ & Extension at yield (Zero slope) $(\mathrm{mm})$ \\
\hline 0.47574 & -11.009 \\
\hline
\end{tabular}

Hence, a symmetry is to be maintained between the porosity and apparent density for precise purposes, since higher mechanical strength corresponds to higher density, while a high porosity provides asurrounding favourable for living organism.

\section{Summary}

In this work, porous scaffolds were prepared using a polymeric sponge template method using cellulose as a binding agent. A welldefined elongated cylindrical HAP crystal with negligible agglomeration was used to fabricate these scaffolds. The FESEM results exposed that the porous Hydroxyapatite scaffolds acquired macro pores and micro pores that emerges to be interconnected with a homogenous porous network. The scaffolds comprise pure crystalline hydroxy apatite phase and no additional phase were produced through the spongy technique as confirmed by XRD and FTIR. The scaffold prepared with cellulose in spite of high porosity (75\%) appeared to report an apparent density of $0.944 \mathrm{~g} / \mathrm{cm} 3$ comparable with trabecular bone $(0.14 \mathrm{~g} / \mathrm{cm} 3$ to 1.10 $\mathrm{g} / \mathrm{cm} 3)$. Thus, it is possible to produce porous scaffolds with varied porosity and density. Such scaffolds canfind its application for tissue engineering in non-load bearing applications or even as a vehicle for thedelivery of biological molecules. Currently, studies are being performed in order to incorporate collagen type I in these porous constructs, to improve their potential application.

\section{Acknowledgement}

This work was supported by DST - FIST under project number (SR-FIST-PSI-193-2014) Department of Physics, Sathyabama Institute of Science and Technology for providing the FT-IR and TGA facilities in characterizing the samples.

\section{References}

1. Woodard JR, Hilldore AJ, Lan SK, Park CJ, Morgan AW, et al. (2007) The mechanical properties and osteoconductivity of hydroxyapatite bone scaffolds with multi-scale porosity. Biomaterials 28: 45-54. [Crossref]

2. Itoh S, Kikuchi M, Takakuda K, Nagaoka K, Koyama Y, et al. (2002) Implantation Study of a Novel Hydroxyapatite/Collagen ( $\mathrm{HAp} / \mathrm{Col}$ ) Composite into Weight-Bearing Sites of Dogs. J Biomed Mater Res 63: 507-515. [Crossref]

3. Sopyan I, Mel M, Ramesh S, Khalid KA (2007) Porous hydroxyapatite for artificial bone applications. Science and Technology of Advanced Materials 8: 116-123.

4. Monmaturapoj N, Yatongchai C (2011) Influence of preparation method on hydroxyapatite porous scaffolds. Bull Mater Sci 34: 1733-1737.

5. Tampieri A, Celotti G, Sprio S, Delcogliano A, Franzese S (2001) Porosity-graded hydroxyapatite ceramics to replace natural bone. Biomaterials 22: 1365-1370. [Crossref]

6. Anita JL, Sundareswari M, Ravichandran K (2016) Porous hydroxyapatite scaffolds for orthopaedicand dentalapplications - the role of binders. Materials Today: Proceedings 3:1672-1677.

7. Anita JL, Sundareswari M, Gill AS, Ravichandran K, Prabhkar JJ (2017) The Role of Cellulose in the Formulation of Interconnected Macro and Micoporous Biocompatible hydroxyapatite Scaffolds. Mechanics, Materials Science \& Engineering P. 9.

8. Anita JL, Sundareswari M, Ravichandran K (2018) Digest Journal of Nanomaterials and Biostructures 13: 235-243.

9. Hollister SJ, Lin CY, Saito E, Lin CY, Schek RD, et al. (2005) Engineering craniofacial scaffolds. Orthod Craniofac Res 8: 162-173. [Crossref]

10. Narbat MK, Orang F, Hashtjin MS, Goudarzi A (2006) Fabrication of Porous Hydroxyapatite-Gelatin Composite Scaffolds for Bone Tissue Engineering. Iranian Biomedical Journal 10: 215-223.

11. Evans LA, Macey DJ, Webb J (1992) Calcium biomineralization in the radular teeth of the chiton, Acanthopleura hirtosa. Calcif Tissue Int 51: 78-82. [Crossref]

12. Khalil KA, Kim WS, Kim HY (2007) Consolidation andmechanical properties ofnanostructured hydroxyapatite- ( $\mathrm{ZrO} 2 \quad 1 \quad 3$ mol\% $\%$ Y2O3) bio-ceramics by highfrequency induction heatsintering. Mat Sci Eng A-Struct 456: 368-372. 